\title{
Beckwith-Wiedemann Syndrome
}

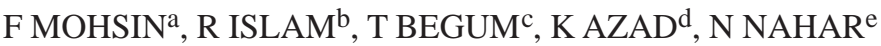

\section{Summary :}

Beckwith-Wiedemann syndrome (BWS) is a disorder of growth regulation characterized by macrosomia, macroglossia and developmental abnormalities with a predisposition to tumour development. The diagnosis of Beckwith-Wiedemann syndrome may be missed because of variable or incomplete clinical expression. Here we present a case of a newborn delivered at BIRDEM (Bangladesh Institute of Research and Rehabilitation in Diabetes, Endocrine and Metabolic

\section{Introduction:}

Beckwith-Wiedemann syndrome (BWS) is a disorder of growth regulation exhibiting somatic overgrowth and a predisposition to embryonal tumors. ${ }^{1}$ It was also known as EMG (Exomphalos, Macroglossia, Gigantism) syndrome which was recognized independently by Beckwith in 1963 and Wiedemann in 1964. ${ }^{2,3}$ The diagnosis of Beckwith-Wiedemann syndrome may be missed because of variable or incomplete clinical expression. Recognition of such patients is important, however, because they have the potential for development of neoplasia. ${ }^{4}$ Here we present a case recently seen at BIRDEM General Hospital in order to create further awareness and highlight peculiarity of management as may be applicable in a setting as ours.

\section{Case Report:}

A male newborn was delivered by caesarian section at 35 weeks pregnancy. There was no history of

a. Dr. Fauzia Mohsin, Associate Professor, Department of Paediatrics, BIRDEM General Hospital and Ibrahim Medical College, Dhaka, Bangladesh

b. Dr. Rubaiya Islam, Senior Medical Officer, Department of Paediatrics, BIRDEM general Hospital

c. Prof.Tahmina Begum, Professor and Head, Department of Paediatrics, BIRDEM General Hospital and Ibrahim Medical College

d. Prof. Kishwar Azad, Senior Honorary Consultant, Department of Paediatrics, BIRDEM General Hospital and Ibrahim Medical College

e. Prof. Nazmun Nahar, Department of Paediatrics, BIRDEM General Hospital and Ibrahim Medical Colllege

Address of Correspondence: Dr. Fauzia Mohsin, Department of Paediatrics, BIRDEM General Hospital and Ibrahim Medical College, Tel: 880-1713063141 (Mobile), Email: fauzia_mohsin@yahoo.com Received: 05 August, 2013

Accepted: 15 April, 2014
Disorders) General Hospital, presenting with macrosomia, macroglossia and hypoglycaemia. The baby also had umbilical hernia and asymmetry of limbs. The case is presented in order to create further awareness and to highlight the peculiarity of management of this rare disorder.

Keywords: Beckwith-Wiedemann Syndrome, Developmental abnormalities.

(J Banagladesh Coll Phys Surg 2014; 32: 167-170)

consanguinity. Mother was 27 years old, primigravida with gestational diabetes mellitus, had pregnancy induced hypertension and polyhydramnios.

Physical examination revealed an active baby with the following anthropometric measurements, weight $3.2 \mathrm{~kg}$ ( $>90^{\text {th }}$ centile), length $51 \mathrm{~cm}\left(>90^{\text {th }}\right.$ centile), head circumference $34 \mathrm{~cm}$ ( $>3^{\text {rd }}$ centile). The baby had impressively large tongue protruding out of the oral cavity (Figure 1). Initially he had mild tachyapnoea and respiratory distress and was diagnosed as a case of preterm, infant of diabetic mother (IDM) with macrosomia, macroglossia and transient tachypnea of newborn (TTN). The tachypnea and respiratory distress was resolved by 24 hours.

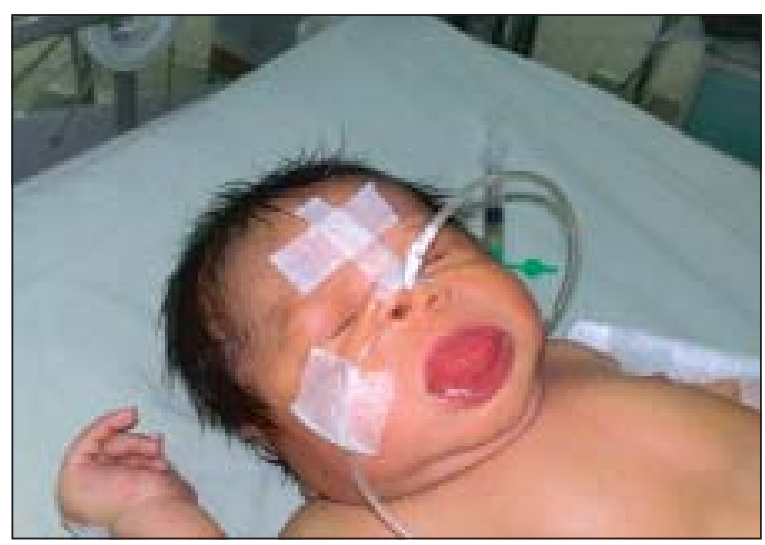

Fig.-1: Newborn with Beckwith-Wiedemann syndrome showing macroglossia

Initially the baby was given oxygen, kept nothing per oral and 10\% dextrose in aqua was started. According to protocol for IDM babies capillary blood glucose as well as formal blood glucose was monitored and baby was normoglycaemic initially. Nasogastric feeding was 
started from day 2 along with intravenous fluid. Inspite of these, the baby developed repeated hypoglycemia from day 2 (RBS $1.9 \mathrm{mmol} / \mathrm{L}$ ). Then the strength of dextrose was increased to $12.5 \%$ and as hypoglycaemia persisted, injectable hydrocortisone was added from day 3 and continued for 3 days. The blood glucose became normal from day 4 onwards. An ultrasound scan of abdomen was done which was normal. Echocardiography showed small atrial septal defect (secundum type), Thyroid function test was normal.

A regular monitoring of blood glucose was continued. The baby again developed hypoglycaemia from day 9 . A blood sample was sent at the time of hypoglycaemia (Blood glucose $1.8 \mathrm{mmol} / \mathrm{L}$ ) for further evaluation which revealed : serum Insulin-11.80 ì/ml (normal value: 2.1-22ìU/ml), serum cortisol-190.70nmol/l (normal value: 116-690 nmol/l) and growth hormone$7 \mathrm{ng} / \mathrm{ml}$ (normal value: 0.05-3ng/ml). His blood $\mathrm{pH}$, serum ammonia and lactate were normal, urine was negative for ketone and reducing substance thus excluding metabolic disorders like galactosemia, glycogen storage disorders etc. In nonhyperinsulinaemic hypoglycaemia, at a blood sample sent at the time of hypoglycaemia which is also known as critical sample, the insulin level should be undetectable or very low ( less than $5 \mathrm{iU} / \mathrm{ml}$ and no higher than $10 \mathrm{iU} / \mathrm{ml}$ ) and cortisol and growth hormone level high. But in hyperinsulinaemic hypoglycaemia, at hypoglycaemic state, plasma insulin is $>5-10 \mathrm{iU} / \mathrm{ml}$ and insulin (iU/ml): glucose $(\mathrm{mg} / \mathrm{dL})$ is $>0.3-0.5 .^{5,6}$ Therefore the results were consistent with that of hyperinsulinaemic hypoglycaemia with an inadequate cortisol response. Persistent hypoglycemia was managed with tablet hydrocortisone for 2 weeks and as the baby maintained normal blood glucose level, hydrocortisone was tapered over next 2 weeks and then stopped. For macroglossia, oral and maxillofacial surgeon was consulted who advised for follow up.

On follow up at six weeks of age, his blood glucose levels were normal and basal serum cortisol level was 395nmol/L, which was normal for his age. The baby was healthy but macroglossia persisted and baby had developed umbilical hernia and mild asymmetry of limbs with right sided hemihypertrophy (Figure 2) which were not apparently evident at birth. On follow up at 4 month of age, the baby was maintaining normal blood glucose. The macroglossia persisted but was not progressing, umbilical hernia and asymmetry of both limbs were more prominent. His weight and length still went parallel to the $90^{\text {th }}$ centile. Development was age appropriate. Serum á-fetoprotein level and follow up ultrasound scan of abdomen were done which were normal.

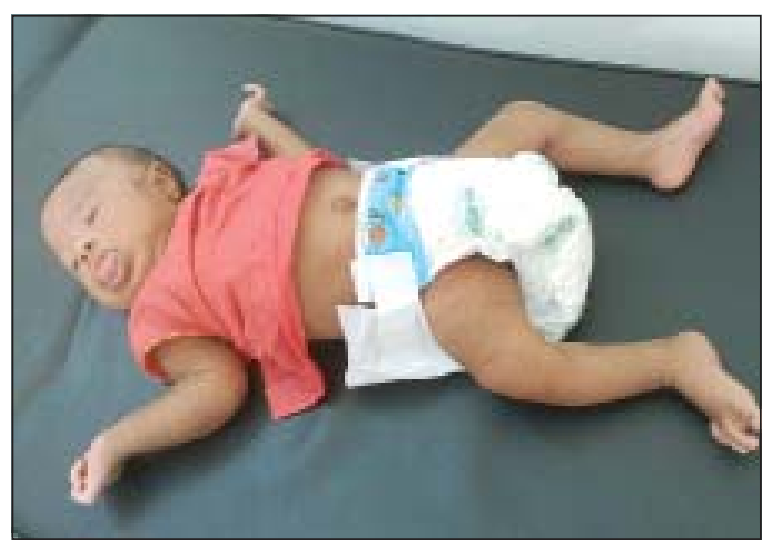

Fig.-2: Baby with Beckwith-Wiedemann syndrome at 6 week showing macroglossia, umbilical hernia and mild asymmetry of limbs

\section{Discussion:}

Beckwith-Wiedemann syndrome (BWS) is clinically and genetically a heterogeneous disorder with an incidence of 1 in 13,700 live births with an equal sex distribution. ${ }^{7}$ The phenotype of BWS is likely to result from an imbalance of a number of critical genes at chromosome $11 \mathrm{p} 15 .^{8}$ In BWS, $85 \%$ of cases are sporadic and $15 \%$ are autosomal dominant. ${ }^{7}$ The risk of recurrence in a family depends on genetic cause of BWS in the proband. Recent reports suggested that assisted reproductive technology (ART) may increase the risk of imprinting disorders and BWS in particular. 9,10 ART may favour imprinting alteration at the centromere of chromosome 11p15 during the preimplantation phase of embryonic development.

Elliott and Maher ${ }^{11}$ identified clinical features for postnatal diagnosis of BWS. Three major features are: anterior abdominal wall defect, macroglossia, pre-or postnatal overgrowth. The minor features are: ear lobe creases, fissures or pits, facial naevus flammeus, hypoglycaemia, nephromegaly, hemihypertrophy. Postnatal diagnosis is based on either three major features, or two major and three minor features. ${ }^{11}$ Based on clinical features our patient fulfilled the criteria for diagnosis of BWS. Of the transient hyperinsulinaemic states, infants of diabetic mothers (IDM) are the most 
common. Although an infant of diabetic mother (IDM), our patient had persistent hypoglycaemia. Persistent hypoglycaemia due to hyperinsulinaemic state can be caused by genetic forms of hyperinsulinism which includes focal and diffuse SUR1 and Kir 6.2 defect, glutamate dehydrogenase defect, glucokinase deficiency. It can also be due to Beck-Wiedemann syndrome, islet cell tumour and factitious hyperinsulinaemia., 5 There was no consanguinity or family history in our patient. Genetic study was not possible in our present context but of the above mentioned conditions, macroglossia and hemihypertrophy was typical of BWS . Reish et $\mathrm{al}^{12}$ made it possible by ultrasound and cytogenetic analysis of the fetus and both parents to diagnose this condition prenatally. Constant ultrasound findings include fetal overgrowth, polyhydramnios, enlarged placenta and specifically a distended abdomen. These signs usually develop after twenty two weeks of gestation. ${ }^{12}$

Macroglossia is the most frequent manifestation of BWS. Like many other physical abnormalities of BWS, it tends to regress with increasing age. Macroglossia may cause feeding problems, speech problems, and/or obstructive apnoea and surgical tongue reduction may be required in severe cases. ${ }^{11}$ Cardiac malformations are found in about $20 \%$ of children with BWS. Approximately half manifest cadiomegaly that resolve spontaneously. ${ }^{13}$ Overgrowth in BWS is most marked in the first few years and is associated with an advanced bone age. It tends to slow down in late childhood and adult heights are generally in the normal range. ${ }^{1}$ Hemihypertrophy occurs in upto $25 \%$ of cases. It is usually evident at birth and often becomes more marked as the child grows. Mild asymmetry may require physiotherapy and conservative orthopedic management. In more severe cases surgical intervention may be performed at puberty. ${ }^{11}$ Hemihypertrophy is also seen in other conditions such as Klippel-TrenaunayWeber syndrome associated with port-wine stain or capillary malformations in the skin and neurofibromatosis. Even isolated hemihyperplasia is associated with an increased risk of embryonal tumour, mainly wilms' tumour and hepatoblastoma. ${ }^{14}$

Hypoglycaemia is reported in $30-50 \%$ of babies with BWS, likely to be caused by islet cell hyperplasia and hyperinsulinaemia. ${ }^{8,13,15}$ Often hypoglycemia is transient, asymptomatic and resolve within the first few days of life. In about 5\% of children, the hypoglycemia can be persistent and extend beyond the neonatal period, requiring either continuous feeding, medical therapy, or, in rare cases, partial pancreatectomy. In this group of children, the hypoglycemia can be severe, causing significant brain damage even death. ${ }^{8,13,15}$ Our patient had repeated hypoglycemia from second day which was managed with nasogastric feeding, intravenous dextrose and injectable hydrocortisone as per standard protocol ${ }^{16}$ and hypoglycaemia resolved. But the baby again developed hypoglycemia from day 9. Hierarchal approach to manage persistent hypoglycaemia due to hyperinsulinism has been outlined by Aynsley-Green et $\mathrm{al}^{17}$ which starts with adequate carbohydrate (oral or intravenous), followed by oral agents such as diazoxide, chlorthiazide and Nifedipine, then use of parental agent such as glucagon and octreotide and finally pancreatic surgery if all medical management fails. ${ }^{17}$ There are also reports of successful treatment of hypoglycaemia with diazoxide, cortisol or glucagon as monotherapy. ${ }^{18}$ As diazoxide was not available and there was inadequate cortisol response, our patient was managed with tablet hydrocortisone.

BWS must be followed for the neoplasia that may present in $7.5 \%$ of patients, most common is wilms' tumor, especially in patients with hemihypertrophy. Other tumors are adrenal carcinoma, hepatoblastoma, neuroblastoma and rhabdomyosarcoma. ${ }^{14,19}$ Most of the tumors associated with BWS occur within first 8-10 years of life with very few being reported beyond this age. Given the importance of early diagnosis, all children with BWS should be screened for cancer. An abdominal ultrasound every 3 months until at least eight years of age and ablood test to measure alpha-fetoprotein (AFP) every 3 months until at least four years of age are recommended. 1,14,19 AFP level should be interpreted with a normal curve established specifically for BWS as AFP can be higher in patients with BWS than in healthy infant and children. ${ }^{20}$

In most patients with BWS, the long term survival is favourable. ${ }^{21}$ Therefore screening for hypoglycaemia and its management is of paramount importance to prevent cognitive impairment. Supportive medical and surgical strategies and cancer screening is important. Genetic counseling regarding etiology and recurrence risk for BWS is most accurate if data from a complete diagnostic evaluation are available, including current molecular testing. 


\section{References:}

1. Weksberg R, Shuman C, Beckwith J B. Beckwith-Wiedemann syndrome. Eur J Hum Genet 2010; 18: 8-14.

2. Bechwith JB: Extreme cytomegaly of the adrenal fetal cortex, omphalocele, hyperplasia of kidneys and pancreas, and leydig cell hyperplasia: Another syndrome? (Abstract). Western society for Paediatric Research 1963, Los Angeles.

3. Wiedemann HR. Complexe Malformatif familial avec hernie ombilcale et macrogossia un syndrome nouveau. J Jenet Hum 1964;13:223-32.

4. Sotelo-Avila C, Gonzalez-Crussi F, Fowler JW. Complete and incomplete forms of Beckwith-Wiedemann syndrome: their oncogenic potential. Paediatrics 1980; 96:47-50.

5. Sperling MA. Hypoglycemia. In: Nelson Textbook of Pediatrics.19 ${ }^{\text {th }}$ Edition 2012. Editors; Kliegman RM, Stanton BF, St. Geme JW, Schor NF, Behrman RE. Elsevier, Saunders, Philadelphia,USA.

6. Chandrashekhar SR, Desai MP. Hypoglycemia in Infancy and Childhood. In: Pediatric Endocrine Disorders. $3^{\text {rd }}$ Edition 2014. Editors; Desai MP, Menon PSN, Bhatia V.Universities Press, India.

7. Li M, Squire JA, Weksberg R. Molecular Genetics of Wiedemann- Beckwith Syndrome. Am J Med Genet 1998; 79: 253-9.

8. Munns CFJ, Batch JA. Hyperinsulinism and BeckwithWiedemann Syndrome. Arch Dis Child (Fetal Neonatal Ed) 2001; 84:67-9.

9. DeBaun M, Niemitz E, Feinberg AP. Association of In vitro fertilization with Beckwith-Wiedemann Syndrome and epigenetic alterations of LIT1 and H19. Am J Hum Genet. 2003;72:156-60.

10. Halliday J, Oke K, Breheny S, Algar E, Amor DJ. BeckwithWiedemann syndrome and IVF: a case-control study. Am J Hum Genet 2004;75:526-8.

11. Elliott M, Maher ER. Beckwith- Wiedemann Syndrome. J Med Genet 1994; 31: 560-4.
12. Reish O, Lerer I, Amiel A, Heyman E,Herman A. WiedemannBeckwith Syndrome. Further prenatal characterization of the condition. Am J Med Genet 2002; 107:209-13.

13. Pettenati MJ, Haines JL, Higgins RR, Wapper RS, Palmer CG, Weaver DD. Wiedemann-Beckwith syndrome: presentation of clinical and cytogenetic data on 22 new cases and review of the literature. Hum Genet 1986; 74: 143-54.

14. Clericuzio C L, Martin R A. Diagnostic criteria and tumor screening for individuals with isolated hemihyperplasia. Genet Med 2009; 11: 220-22.

15. Hussain K, Cosgrove K E., Shepherd R.M, Luharia A, Smith $\mathrm{W}$, Kassem S et al. Hyperinsulinemic hypoglycemia in Beckwith-Wiedemann Syndrome due to defects in the function of pancreatic â-Cell adenosine triphosphate-sensitive potassium channels. J Clin Endocrinol Metab 2005; 90:4376-82.

16. Wilker RE. Hypoglycaemia and hyperglycaemia In: Manual of neonatal care. $7^{\text {th }}$ edition 2012. Editors; Cloherty JP, Eichenwald EC, Hansen AR, Stark AR. Lippincott Williams and Wilkins, Philadelphia, USA.

17. Aynsley-Green A, Hussain K, Hull J, Saudubray JM, NihoulFekete C, Lonlay-Debeney PD et al. Practical management of hyperinsulinism in infancy. Arch Dis Child fetal Neonatal Ed 2000; 82:F98-107.

18. Coombs J, Grunt J, Brandt I. New syndrome of neonatal hypoglycaemia associated with visceromegaly, macroglossia, microcephaly and abnormal umbilicus. N Eng J Med 1966; 275; 236-43.

19. Choyke PL, Siegel MJ, Craft AW, Green DM, DeBaun MR. Screening for Wilms tumor in children with BeckwithWiedemann syndrome or idiopathic hemihypertrophy. Med pediatr oncol 1999; 32: 196-200.

20. Everman DB, Shuman C, Dzolganovski B, O’Riordan MA, Weksberg R, Robin MH. Serum alpha-fetoprotein levels in Beckwith-Wiedemann syndrome. J Pediatr 2000; 137: 123-7.

21. Weng E, Mortier G, Graham J. Beckwith-Wiedemann syndrome. Clin Pediatr 1995; 34:317-26. 